\title{
A Brief Discussion on College Teacher's Science Research Burnout
}

\author{
Chunhua Shi ${ }^{1 *}$ and Baojun Wang ${ }^{2}$ \\ ${ }^{1}$ Institute of Applied Psychology, Hohai University, Nanjing 211100, China \\ ${ }^{2}$ Institute of the Earth Sciences and Engineering, Nanjing University, Nanjing 210046, China \\ ${ }^{*}$ Corresponding author
}

Keywords: Job burnout; science research burnout; science research orientation; college teachers.

\begin{abstract}
In China, because many universities pay too much attention to scientific research(SR)and take no account of teaching, the pressure on SR is too great, which easily leads to the scientific research burnout(SRB)among college teachers. It was suggested in the article that the SRB belongs to the category of job burnout, but it is a relatively new conception which means college teachers can't adapt to the current SR evaluation systems, having difficulties in finishing research targets. By reviewing the empirical research and theories, the conceptual meaning, external and internal causes of SRB were briefly discussed. In particular, the idea that two groups of college teachers who are more likely to suffer SRB was put forward. The purpose of this article was to provide a reference for the theoretical research and practical solution of SRB in the future.
\end{abstract}

\section{Introduction}

At present, it's obvious that the scientific research(SR)orientation is very prevalent in many colleges and universities in the mainland of China [1][2].The universities there have become more and more prominent in their SR function since the 1990s, which is related to many complicated reasons such as the Chinese basic state policies of rapidly developing economy, the ranking of universities, subordinates' obedience to superiors and the administration orders in the administrative management of universities, the social values of being eager for quick success and instant benefit and so on.

The so-called SR orientation refers to the certain deviations in university evaluation systems influencing especially the professional title upgrading, the qualified or unqualified year-end and employment term assessment, and the performance-related pay. Its key characteristic is the teaching and education being ignored to a considerable extent while SR being placed in the center of university functions.

It is undoubted that the SR orientation increases greatly SR pressure on college teachers[1][2]. A large number of empirical studies in management psychology both at home and abroad has already shown that job burnout [3]is closely related to the working environment, and the excessive work stress is one of the important factors leading to job burnout. There are many empirical studies on job burnout of college teachers at home and abroad, but few on scientific research burnout (SRB)[4]. We argued that the reasons for this may be that domestic universities have for a long time orientated their main functions to teaching rather than SR, while foreign ones may have a relatively relaxed and comfortable SR environment owing to their different social and cultural background. Therefore in the article we discussed briefly on this new theme to support the theoretical and practical exploration, which is beneficial to the promotion of both health and productivity for college teachers as well as universities.

\section{The Conception and Its Measure of SRB}

Up to now, only Zhang, a Chinese scholar[4] has formally put forward the concept of college teachers' SRB and compiled it's measurement. According to Zhang, SRB refers to all kinds of adverse psychological reactions, such as the emotions of anxiety, fatigue, low sense of efficacy, powerlessness, etc., produced by the failure of fulfilling research objectives which are the expectations of universities, needed by professional title promotion or driven by self-achievement motivations. Inspired by Zhang, we argued that the concept of SRB is a relatively new form of job burnout, triggered by SR and directed to 
SR, and it is especially applicable to the social group of college teachers. It is worth noting that SRB is very different from the general job burnout of college teachers, which involves all the professional activities, such as teaching, relations with colleagues, student management, social services and so on. The traditional sense of college teachers' job burnout is mainly related to the burden of teaching knowledge, difficulties in cultivating personality and the complexity of communicating with other teachers, less about SR.

Consistent with Maslach's classical structure of job burnout[3], SRB also has three dimensional structures, i.e. emotional exhaustion(e.g. When it comes to writing scientific papers, I feel exhausted), low achievement (e.g. I am not very good at publishing SR papers)and cynicism(e.g. Every time when I see low quality papers published in high quality journals, I feel it is only so-so). The final scale of SRB contains 22 items with a good internal consistency reliability and criterion-related validity(The criterion is the general self -efficacy),which indicates it is suitable for measuring SRB among college teachers in China[4]. We believed now that SRB has the color of social disapproval, it is needed in the future to measure it both explicitly and implicitly at the same time to examine the validity of the explicit measuring tool of SRB.

\section{External Causes of SRB}

\subsection{The SR as an inflexible or stringent requirement.}

According to Lazarus's theory of stress-related transactions between person and environment[5], college teachers' SR pressure can be defined as the discomfort they experience when they are forced to deviate from their normal life style due to both job requirements and selves expectations.

The SR performance management has been adopted in many universities. It is a certain number of research projects and papers with higher level, in some engineering and science subjects, patents being also included, that becomes the most important indicators to measure the SR ability and level of college teachers. Other minor indicators may include attending international or domestic professional conferences and at the same time making speeches in them. In fact, how well college teachers accomplish SR tasks has become the irreplaceable key examination contents that will decide to a considerable extent the results of year-end and appointment period evaluation, promotion of professional titles, award-winning, and talent programs, which will then affect the subject assessment, and then the university ranking. Under these circumstances, college teachers have to bear huge pressure, furthermore it has a continuous trend to increase in the next few years.

\subsection{The imperfection of the support and evaluation mechanism of SR.}

It's known without proof that to complete SR, college teachers have to involve a series of difficulties and obstacles such as the project application, project approval, trials and experiments, articles writing and publication, appraisal of achievements in SR and so on. In other words, the SR itself is a complicated and risky task involving multiple activities including both mental and physical labor as well as emotion labor which means the communication with colleagues and the upper level to get interpersonal support or avoid direct and indirect interpersonal obstruction. Therefore, if there is something wrong in any of these elements or their corporation, then the failure can't be avoided.

According to a semi-structured interviews conducted to 48 college teachers from 6 universities in Fujian, Shanxi and Beijing, it was shown that there exists the rigid requirement for quantitative assessment of SR and the SR guarantee mechanism is relatively poor, which are the main reasons why college teachers are under great pressure and become indifferent to SR[1]. In a survey of 385 college teachers from 7 universities, it was found that the intensive SR tasks together with the invalid evaluation methods, of which the prominent characteristics are short checkup cycle, high frequent evaluation, fast results and bigger return, will hurt seriously college teachers' enthusiasm for SR. The high demand combined with low resources has led to job burnout of college teachers, and thus the reduction of mental health level[2]. 


\subsection{Disadvantages of circle culture and professionalism.}

It is well known the traditional Chinese society is a society of human relationship and also a society with official orientation. Therefore even nowadays and in the academic field, this inertia of thoughts and behaviors still exists to a certain degree. Such problem is outstandingly reflected as the importance of human relation and authority greater than SR itself to some extent, lacking academic fairness and justice. In addition, the professionalism of college teachers also makes it easy for them to abandon their traditional academic conscience, which is mainly manifested by blindly pursuing hot spots, following the authority, making some simple supplements to foreign or authoritative research. To sum up, when college teachers regard themselves only knowledge workers working for enterprises engaged in knowledge selling, they will ignore the real creation and significance of SR, which in turn make themselves lose creativity and scientific spirit in SR.

The top labs in 5 key universities in Wuhan were investigated, it found work alienation (which mainly suggests job burnout) is in the middle level; the level of irregularity (which means the universities lacking definite rules) is relatively high; all the faculty's perception of organizational politics, job characteristics and work stress can predict the work alienation, but it is the perception of organizational politics which has the greatest influences. The conclusion was that the traditional factors (human relations, authority) impact the faculty further more than the reforming factors [6].

\section{Internal Causes of SRB}

In any case, SRB is related to the failure to meet the requirements of the university current performance appraisal systems. Why is there a big difference in the degree of SRB under the same external environment and conditions? In light of our observation, SRB involves mainly two groups of college teachers. Some people, especially the middle aged and professors, who would rather do SR according to their own ideas than conform to the SR task indicators designed by university's SR systems. They insist on doing what they think is valuable and interesting for them although they usually have to accept direct or indirect hints and criticisms from the line managers, also the good or bad understanding and jokes from colleagues and family members. From this group of people, we can see clearly that the SRB concerns more with the lower level of adapt and conformity than with the lower level of responsibility and scientific spirit. Nevertheless, we can not deny that this group of people tends to have a kind of character with excessive perfectionism, low willingness to abide by rules or communicate with line managers. We can further deduce that if these people can regulate their individuality appropriately, it will not only reduce their own symptoms of SRB, but also make the SR evaluation systems move towards a reasonable orbit faster.

Some of the college teachers, who have been lecturers/ associate professors for many years, and have not been promoted to associate professors/ professors, are likely to belong to the second group. In fact, most of them try to follow up the realistic trend and adapt to the SR evaluation system but have failed at last. Perhaps the biggest problem they face is that they don't understand why they've worked so hard but still can't meet the demands of the current SR system. In particular, they feel angry and confused about the fact that most of the young college teachers who have just graduated from universities with a doctorate seem very easy to grasp the characteristics of the current SR systems and quickly adapt to them. Therefore it is them who may become the most serious group of SRB. So they also need to reflect on their successes and failures, either to put aside the excessive honor and learn modestly from the experience of young people, or to be willing to do what they want to do and what they think is worth doing without much attention to fame and fortune. In fact, the two ways are not entirely incompatible. This requires them to have a reflective personality, accept imperfect self, and make creative transformation and synthesis., which belongs to the modern nursing system that can be applied here[7].

To sum up, many internal variables such as the professional titles, age, characteristics may affect whether or not a college teacher has SRB or its degree. 


\section{Summary}

SRB is a relatively new conception belonged to the category of job burnout. There are complex reasons for its emergence, and it is possible there are some differences about it at home and abroad. Therefore the comparative studies should be conducted in the future. We should also conduct further study to examine its present situation, characteristics, influencing factors, mechanisms and solutions, which will be beneficial for both university teachers and organizations.

\section{Acknowledgement}

This work was financially supported by General Project of Higher Education Teaching Reform in Jungian Province (2017JSJG088); Major Research Project of Higher Science Education Study by Professional Committee of China Higher Education Association of Science Education; Fundamental Research Funds for the Central University(Grand No.2017B606X14).

\section{References}

[1] Z. Liang and Y. Zhang, Characters and causes of scientific research burnout on university faculty, Journal of Shenyang University, vol.23, pp.101-104, 2011. (In Chinese)

[2] L. Zhang and D. M. DeJoy, Work addiction and mental health among university teachers: mechanism of burnout and loneliness, Psychological exploration, vol.32, pp.177-182, 2012. (In Chinese)

[3] C. Maslach and S. E. Jackson, The measurement of experienced burnout, Journal of Occupational Behaviour, vol.2, pp.99-113, 1981.

[4] Q. Zhang, Z. Yan and J. Lu, The development, reliability and validity analysis of the college teacher's science-research burnout inventory, Psychological exploration, Vol.35, pp.84- 89, 2015. (In Chinese)

[5] R. S. Lazarus and R. Et Launier, Stress-related transactions between person and environment, In: L. A. Pervin, M. Lewis, Eds., Perspectives in interactional Psychology, Plenum, New York, 1978, pp. 287-327.

[6] H. Yu, P. Jing, Z. Wang and Y. Fang, What factors led to work alienation of faculty: the survey of the top labs in 5 key universities, Journal of higher education, vol.37, pp.57-63, 2016. (In Chinese)

[7] D. S. Corry, C. A. Lewis and J. Mallett, Harnessing the mental health benefits of the creativityspirituality construct: introducing the theory of transformative coping, Journal of spirituality in mental health, vol. 16, pp.89-110,2014. 